\title{
Vivências de professoras dos Anos Iniciais no trabalho com a resolução de problemas em uma formação continuada
}

Resumo: Este artigo tem como objetivo investigar as vivências de professoras dos Anos Iniciais do Ensino Fundamental no trabalho com a resolução de problemas a partir da unidade temática Números da Base Nacional Comum Curricular (BNCC) e na oficina Brincando, cantando, jogando $e$ problematizando também se aprende a Matemática! Para a produção dos dados foram utilizados um questionário e os registros da oficina, que teve duração de 16 horas. Os participantes foram 15 professoras dos Anos Iniciais. As bases do Interacionismo Sociodiscursivo (ISD) permitiram compreender as representações textualizadas construídas pelo grupo de professoras no âmbito da formação continuada. No desenvolvimento das atividades propostas e criadas na oficina, as dimensões do agir docente individual e coletivo possibilitaram às professoras, em parceria com a formadora, estudar, vivenciar e analisar criticamente o texto prescritivo da área de Matemática na BNCC, fazendo as alterações necessárias nos textos do trabalho planificado e realizado, as quais proporcionaram às professoras conhecer e participar da dinamização da metodologia da resolução de problemas na formação continuada.

Palavras-chave: Formação continuada. Números. Resolução de problemas. BNCC. Agir docente.

\section{Experiences of teachers from Early Years at work with problem solving in continuing education}

Abstract: This article aims to investigate the experiences of teachers from the Early Years of Elementary School at work with problem solving from the thematic unit Numbers at the National Curriculum Common Base (BNCC) and at the workshop Playing, singing, playing and also problematizing you learn Math! For the production of the data, a questionnaire and the workshop records, which lasted 16 hours, were used. Participants were 15 teachers from the Early Years. The bases of Sociodiscursive Interactionism (ISD) made it possible to understand the textual representations constructed by the group of teachers in the context of continuing
Sandra Alves de Oliveira

Doutoranda em Educação. Professora do Colégio Municipal Aurelino José de Oliveira e Professora do

Departamento de Educação da

Universidade do Estado da Bahia

(UNEB), campus Guanambi. Bahia,

Brasil.

orcid.org/0000-0002-7804-7197

$₫$ sandraoliveira.uneb@gmail.com

Dayselane Pimenta Lopes

Rezende

Doutoranda em Educação.

Coordenadora Pedagógica da Secretaria Municipal de Educação de Varre-Sai e da Secretaria Municipal de Educação de Porciúncula. Rio de Janeiro, Brasil.

iD orcid.org/0000-0001-8846-3234 $\bowtie$ lanedayse@gmail.com

Andreia Rezende Garcia Reis

Doutora em Linguística. Professora do Programa de Pós-Graduação em

Educação da Universidade Federal de Juiz de Fora (UFJF). Minas Gerais, Brasil.

(iD orcid.org/0000-0003-1209-5185

$\triangle$ andreiargarcia@yahoo.com.br

Reginaldo Fernando Carneiro

Doutor em Educação. Professor do Programa de Pós-Graduação em Educação e do Programa de Pós-

Graduação em Educação Matemática, ambos da Universidade Federal de Juiz de Fora (UFJF). Minas Gerais, Brasil.

iD orcid.org/0000-0001-6841-7695

$₫$ reginaldo_carneiro@yahoo.com.br

Recebido em 29/06/2020 Aceito em 03/01/2021

Publicado em 05/01/2021 
education. In the development of the activities proposed and created in the workshop, the dimensions of individual and collective teaching action enabled teachers, in partnership with the trainer, to study, experience and critically analyze the prescriptive text in the area of Mathematics at BNCC, making the necessary changes in the texts the planned and accomplished work which enabled teachers to know and participate in promoting the methodology of problem solving in continuing education.

Keywords: Continuing education. Numbers. Problem solving. BNCC. Acting teacher.

\section{Vivencias de maestras de la Educación Primaria en trabajo con la resolución de problemas en una formación continuada}

Resumem: Este artículo tiene como objetivo investigar las vivencias de maestras de la Educación Primaria en el trabajo con la resolución de problemas a partir de la unidad temática Números de la Base Nacional Común Curricular (BNCC) y en el taller Jugando, cantando, jugando y problematizando también se aprende Matemáticas! Para la recogida de datos fueron utilizados un cuestionario y los registros del taller, que tuve duración de 16 horas. Los participantes fueron 15 maestras de la Educación Primaria. Las bases del Interaccionismo Sociodiscursivo (ISD) permitieron comprender las representaciones textuales construidas por el grupo de maestras en el ámbito de la formación continuada. En el desarrollo de las actividades propuestas y creadas en el taller, las dimensiones del actuar docente individual e colectivo posibilitaron a las maestras, en conjunto con la formadora, estudiar, vivenciar y analizar críticamente el texto prescriptivo del área de Matemática en la BNCC, haciendo los cambios necesarios en los textos del trabajo planificado y realizado, los cuales proporcionaron a las maestras conocer y participar de la dinamización de la metodología de la resolución de problemas en la formación continuada.

Palabras clave: Formación continuada. Números. Resolución de problemas. BNCC. Actuar docente.

\section{Introdução}

Nesta pesquisa, compartilhamos os momentos experienciados com o estudo e a vivência da resolução de problemas no âmbito de uma formação continuada em uma rede municipal de ensino de uma cidade do interior de Minas Gerais, cenário da investigação desenvolvida com os pares.

Numa interação colaborativa e dialógica, nas práticas pedagógicas realizadas no ambiente de formação, professores da universidade e da escola básica manifestaram o desejo de conhecer e aprofundar teoricamente e na prática a área de Matemática na Base Nacional Comum Curricular (BNCC), valorizando as propostas dos Parâmetros Curriculares Nacionais (PCN) e de programas de formação continuada produzidos por professores e especialistas da comunidade de Educação Matemática e de outras áreas do 
conhecimento que contribuíram para os processos de ensino-aprendizagem da Matemática e para o desenvolvimento profissional docente como um processo contínuo e evolutivo que se prolonga ao longo da vida (GARCÍA, 2011; MIZUKAMI et al., 2006).

$\mathrm{Na}$ formação continuada, buscamos apresentar, discutir e vivenciar os objetos do conhecimento e as habilidades propostos nas unidades temáticas Números, Álgebra, Geometria, Grandezas e Medidas, Probabilidade e Estatística, da área de Matemática do Ensino Fundamental (BRASIL, 2017). Essas unidades foram vivenciadas teoricamente e na prática, em cinco encontros formativos realizados no ano de 2019, com a participação da professora formadora-pesquisadora, do professor coordenador da formação e dos 57 professores da Educação Básica de uma rede municipal de ensino, que voluntariamente se inscreveram e participaram da formação continuada em Matemática.

Utilizamos as bases do Interacionismo Sociodiscursivo (ISD) para compreender as representações textualizadas de um grupo de professores dos Anos Iniciais do Ensino Fundamental sobre a resolução de problemas proposta na BNCC, na relação com o "trabalho prescrito, trabalho planificado e trabalho realizado na análise da atividade de formação de professores" (MACHADO, 2002, p. 40) e dos elementos constitutivos do trabalho docente (CORRÊA, 2014).

O trabalho prescrito, segundo Bronckart (2008, p. 132), “é constituído por documentos produzidos pelas instituições ou empresas com o objetivo de preparar, organizar e planificar o trabalho". Para Machado (2002, p. 41), "os textos de planificação explicitam o conjunto de tarefas, seus objetivos, suas condições materiais e a forma de desenvolvimento das ações projetadas pelo próprio trabalhador para atingir seus objetivos" propostos nas atividades desenvolvidas. Para que o trabalho realizado seja efetivado, conforme essa autora, há uma (re)configuração das prescrições pelo professor. Nesse trabalho é utilizado um "conjunto de condutas (verbais ou não verbais) efetivamente observáveis na situação, que sempre vai apresentar algum distanciamento em relação ao que lhe foi prescrito" (MACHADO, 2002, p. 41).

Neste artigo, apresentamos e discutimos um recorte dos encontros formativos, que teve como questão norteadora: quais as vivências do trabalho efetivamente realizado com a resolução de problemas, nos textos produzidos pelos professores na formação continuada? Como objetivo, buscamos investigar as vivências de 15 professoras dos Anos 
Iniciais do Ensino Fundamental no trabalho com a resolução de problemas a partir da unidade temática Números na BNCC e na oficina Brincando, cantando, jogando e problematizando também se aprende a Matemática!

\section{Reflexões sobre o trabalho docente, a atividade e o agir formativo no âmbito da formação continuada em matemática}

De acordo com Bronckart (2006, p. 209), o trabalho é considerado como uma forma de agir, "como um tipo de atividade ou de prática [...] própria da espécie humana", que se desenvolve por meio de atividades organizadas coletivamente no percurso formativo. Com efeito, o trabalho do professor como uma atividade teórica e prática não é isolado, mas coletivo, inserido num contexto sócio-histórico no sistema de ensino e no sistema educacional específico (MACHADO e BRONCKART, 2009).

Em relação ao trabalho do professor, Amigues (2004, p. 42) salienta que "a relação entre a prescrição inicial e sua realização junto aos alunos não é direta, mas mediada por um trabalho de concepção e de organização de um meio que geralmente apresenta formas coletivas" para o desenvolvimento da tarefa e da atividade.

Esse autor vincula a tarefa "ao que deve ser feito e pode ser objetivamente descrita em termos de condições e de objetivo, de meios (materiais, técnicos...) utilizados pelo sujeito. A atividade corresponde ao que o sujeito faz mentalmente para realizar essa tarefa" (AMIGUES, 2004, p. 39).

Para Souza-e-Silva (2004, p. 93), "realizar uma tarefa não consiste apenas em atingir os objetivos propostos, mas implica também a realização de um projeto, de uma intenção a partilhar com os alunos; portanto, o meio, o grupo e o desenvolvimento da atividade são indissociáveis" no agir docente, no trabalho interativo com o outro.

O trabalho prescrito, segundo Bronckart (2006, p. 208), “constitui-se como uma representação do que deve ser o trabalho, que é anterior à sua realização efetiva; portanto, os projetos didáticos, os programas, os manuais e as sequências didáticas pertencem a esse nível”.

Neste artigo, compartilhamos um recorte das prescrições referentes à resolução de problemas na unidade temática Números, que "não servem apenas como desencadeadoras 
da ação do professor, sendo também constitutivas de sua atividade" (AMIGUES, 2004, p. 42) formativa, mobilizada por um coletivo de profissionais que voluntariamente se inscreveram no curso de formação continuada para estudar e compreender os fundamentos teóricos e práticos das unidades temáticas da área de Matemática na BNCC. Esse documento curricular destaca que "em todas as unidades temáticas, a delimitação dos objetos de conhecimento e das habilidades considera que as noções matemáticas são retomadas, ampliadas e aprofundadas ano a ano" (BRASIL, 2017, p. 274).

Com efeito, é importante a formação do professor que ensina Matemática, para que possa entender os conceitos matemáticos a serem retomados, ampliados e aprofundados ano a ano nas unidades temáticas da área de Matemática nos Anos Iniciais do Ensino Fundamental.

No âmbito da formação continuada em Matemática, a formadora buscou apresentar e discutir os textos prescritivos das unidades temáticas, levando em consideração a proposta dos Parâmetros Curriculares Nacionais (PCN), do Programa Gestão da Aprendizagem Escolar (GESTAR) de Matemática (2008), do Pró-Letramento (2012), do Pacto Nacional pela Alfabetização na Idade Certa (PNAIC) de Matemática (2014), dentre outras ações. Também compartilhou resultados de pesquisas acadêmicas sobre a formação de professores que discutem sobre Números e outros temas matemáticos.

Para estudo e vivência de atividades focando essa unidade temática, a formadora elaborou o plano de formação que contemplou a realização de oficinas pedagógicas nos encontros formativos, constituindo assim um texto de planificação, "uma vez que nele se definem as ações específicas (ou tarefas) que os diferentes agentes deveriam realizar, as responsabilidades de cada um, suas etapas, seus objetivos, os resultados desejados, as ferramentas a serem utilizadas, os contextos a serem criados" (MACHADO, 2002, p. 45). Conforme essa autora, é um texto concernente ao trabalho realizado, visto que as ações propostas no planejamento foram aceitas e vivenciadas pelos professores envolvidos na formação.

Os dados foram obtidos a partir de um questionário e dos registros da oficina Brincando, cantando, jogando e problematizando também se aprende a Matemática!, que teve duração de 16 horas, em que os participantes discutiram textos, relataram 
experiências de sala de aula, participaram de rodas de conversa sobre a resolução de problemas na BNCC e de diferentes dinâmicas, elaboraram e resolveram situaçõesproblema, vivenciaram jogos, entre outras atividades.

A resolução de problemas deve ser discutida e investigada na formação de professores, pois é uma metodologia de ensino que pode promover a aprendizagem dos conceitos e conteúdos matemáticos, mas também que os alunos apresentam dificuldades (BUENO, ALENCAR e MILLONES, 2017) como não conseguir interpretar a situação proposta ou não saber transformar em termos matemáticos o enunciado e a pergunta.

$\mathrm{Na}$ formação continuada, a professora-formadora mobilizou o grupo de professores para analisar a proposta da Matemática na BNCC, partindo dos saberes, das experiências e das aprendizagens da prática docente. Buscou-se criar perspectivas metodológicas para discutir os objetos do conhecimento e as habilidades, propostos nas unidades temáticas da Matemática dos Anos Iniciais do Ensino Fundamental, tais como: vivências de dinâmicas, jogos, brincadeiras, conto de histórias infantis, dinamização de músicas, resolução de problemas, dentre outras.

Considerando a abrangência dos dados obtidos na formação continuada, selecionamos 15 professoras dos Anos Iniciais por meio da lista de frequência, sendo três professoras do $1^{\circ}, 2^{\circ}$ e $3^{\circ}$ anos, duas professoras do $4^{\circ}$ ano e quatro professoras do $5^{\circ}$ ano. Essas professoras foram escolhidas devido ao interesse em participar da pesquisa e, também, por apresentarem discussões interessantes em relação à Matemática ao longo da formação continuada. Vamos designá-las por nomes fictícios para preservar a sua identidade: Ana, Beatriz, Carla, Carolina, Catarina, Edna, Fernanda, Gabriela, Letícia, Manuela, Marta, Natália, Patrícia, Sônia e Zélia.

A professora-formadora, em parceria com os professores, para compreender os textos prescritos na BNCC sobre Números, utilizou-se do agir formativo como uma forma de intervenção orientada, mobilizada pelas dimensões motivacionais e intencionais, organizadas pelo coletivo (BRONCKART, 2006) que esteve presente nos encontros formativos no primeiro e segundo semestres de 2019.

No desenvolvimento das atividades no âmbito da formação continuada em Matemática, a professora-formadora buscou mobilizar seu ser integral, em suas diferentes dimensões - físicas, cognitivas, linguageiras, afetivas etc. — , criando possibilidades de 
aprendizagens de conteúdos matemáticos, apresentados, discutidos e vivenciados no contexto das unidades temáticas propostas na BNCC, por meio de orientações prescritas e por modelos do agir apropriados pela formadora e desenvolvidos em interação com os professores, mediante a utilização de recursos didáticos disponibilizados pelo meio social (MACHADO e BRONCKART, 2009).

No percurso do trabalho docente na formação continuada, os professores tiveram oportunidade de produzir textos no contexto das unidades temáticas propostas na BNCC.

\section{A perspectiva do Interacionismo Sociodiscursivo para análise do trabalho docente}

O Interacionismo Sociodiscursivo (ISD) destaca o trabalho como atividade importante para o desenvolvimento do ser humano. De acordo com Corrêa (2014, p. 372), "o projeto do ISD é caracterizado por uma psicologia que deve considerar as ações humanas em suas dimensões sociais e discursivas constitutivas" das formas de agir social, por meio das produções verbais desenvolvidas no decorrer dessa ação (BRONCKART, 2008).

Para o ISD, segundo Corrêa (2014, p. 373), “é central a noção de agir. A atuação do ser humano se dá de modo cooperativo, ou seja, os indivíduos cooperam uns com os outros na atividade, a qual ocorre em constante interação social, sendo mediada pela linguagem". Nos processos formativos esse agir é importante, visto que a cooperação propicia o desenvolvimento da atividade de forma interativa, possibilitando assim uma aprendizagem colaborativa do trabalho prescrito, planificado e realizado numa relação mútua.

Essa atividade de interação é conceituada por Habermas (1989) como agir comunicativo, que "considera que as representações são como signos, isto é, funcionam como representações comuns, compartilháveis e comunicáveis" nos processos interativos (CORRÊA, 2014, p. 373).

O ISD constitui a base teórico-metodológica e interpretativa deste trabalho, pois apresenta fundamentos teórico-metodológicos referentes ao trabalho prescrito, planificado e realizado, que auxiliaram nas categorias de análise que compartilham "os 
textos que materializam o agir humano, podendo contribuir para clarificar e transformar esse agir" (BONOTTO, 2017, p. 61) no percurso formativo da formadora e dos professores que se encontraram para analisar e discutir criticamente a área de Matemática nos anos iniciais do ensino fundamental apresentada na BNCC.

Neste artigo, apresentamos o recorte do trabalho com a resolução de problemas na unidade temática Números, considerando os pressupostos teórico-metodológicos do ISD nesse percurso formativo, "que toma como base a atividade discursiva do desenvolvimento humano e seus processos de mediação" (MAGALHÃES, 2015, p. 104) para dinamizar a metodologia da resolução de problemas na formação continuada e em aulas de Matemática dos professores participantes dos encontros formativos.

O ISD analisa "as condutas humanas como ações significantes, ou como 'ações situadas', cujas propriedades estruturais e funcionais são antes de mais nada, um produto da socialização" (BRONCKART, 1999, p. 13), que envolve "as relações entre pares para a construção de conhecimentos e de competências" (SAUSAT, 2004, p. 20) no agir docente e comunicativo, nos textos apresentados e discutidos na formação continuada em matemática.

No trabalho com a resolução de problemas, as condutas humanas nas relações com os pares na vivência dessa metodologia, a partir da formação de grupos para resolução de problemas propostos, possibilitaram o envolvimento dos professores no processo da leitura, na elaboração de estratégias para resolução do problema e na socialização dos resultados, com o incentivo e a mediação da professora-formadora nas discussões para a dinamização dos momentos "antes, durante e depois" (VAN DE WALLE, 2009, p. 61) e do roteiro para desenvolver de forma mais produtiva a metodologia (ANDRADE e ONUCHIC, 2017; ONUCHIC, 1999; ONUCHIC e ALLEVATO, 2011; OLIVEIRA e PASSOS, 2014), o que propiciou aos professores compartilharem as diferentes soluções para cada problema resolvido.

As interações sociais mediadas pela linguagem são consideradas por Bronckart (1999) como constitutivas do ser humano, nas relações entre os interlocutores e seu ambiente natural durante o trabalho docente, que é considerado por Tardif e Lessard (2009, p. 20) como "trabalho interativo", que "parece um dos principais vetores de transformação atuais da organização socioeconômica das sociedades modernas 
avançadas". Com efeito, o trabalho do professor se articula nas interações com os estudantes e os profissionais da escola e, na formação continuada, insere-se nas relações entre a formadora e os professores.

Nos encontros formativos na formação continuada estão entrelaçados os discursos que propiciam novas possibilidades para compreender o trabalho docente por meio do diálogo entre os pares nas ações do grupo nas escolas em que os professores atuam. Com efeito, as trocas de experiências, os enunciados estão repletos de palavras dos outros que trazem consigo a expressividade e o valor daquilo que assimilamos, reelaboramos e modificamos nas interações verbais (BAKHTIN, 2011).

Nessa perspectiva, o ISD propõe o nível das mediações formativas desenvolvidas em locais de formação com profissionais de estatutos diversos, que buscam utilizar "uma leitura do agir que envolve dimensões motivacionais e intencionais mobilizadas no nível coletivo" (BRONCKART, 2008, p. 121) de seres humanos que interpretam os textos orais ou escritos, por meio do uso da linguagem e do agir comunicativo.

De acordo com Corrêa (2014, p. 374), “o texto é, portanto, uma unidade central para o ISD, haja vista que, ao mesmo tempo em que é capaz de revelar as representações dos agentes, tem o poder de incidir sobre essas representações" nas práticas desenvolvidas nos processos formativos.

O texto, como objeto de análise no âmbito da formação docente, parte do princípio de que, no ISD, "as ações humanas não podem ser apreendidas pela mera observação das condutas perceptíveis, mas por meio de interpretações produzidas via linguagem, em textos dos próprios actantes ou de observadores dessas ações" (CORRÊA, 2014, p. 374). Por essa razão, os participantes da formação continuada buscaram interpretar as ações desenvolvidas nos encontros formativos, por meio da observação dos momentos experienciados em textos prescritos e em textos produzidos pelos actantes, numa relação dialógica e discursiva; e expressaram seus saberes, experiências e aprendizagens em relação à matemática na sua trajetória profissional.

Para o ISD, segundo Garcia-Reis e Silva (2019, p. 90), "é fundamental discutir a importância do trabalho para o desenvolvimento tanto da espécie quanto do indivíduo". Com isso, Bronckart (2006) define claramente que o trabalho se constitui como um tipo de atividade ou de prática determinado pelo agir praxeológico e pelas ações linguageiras 
em práticas sociais.

Visando compreender quais elementos constitutivos do agir docente são tematizados nas relações entre a prescrição, a planificação e o trabalho efetivamente realizado, na formação continuada, nos textos produzidos pelos professores que orientaram as práticas com a resolução de problemas proposta na BNCC, utilizamos a abordagem conceitual do ISD, baseando-nos nos passos apresentados por Garcia-Reis e Silva (2019) a seguir:

1) Leitura da área da Matemática nos Anos Iniciais do Ensino Fundamental no documento Base Nacional Comum Curricular (BNCC) e nos textos das oficinas da formação continuada em Matemática, identificando o trabalho com a resolução de problemas.

2) Pesquisa dos termos "problemas e resolução de problemas" na área de Matemática nos Anos Iniciais do Ensino Fundamental, destacando a unidade temática Números, proposta na BNCC.

3) Avaliação e análise das estruturas frasais que continham os termos pesquisados para identificação dos elementos constitutivos do agir docente tematizados no trabalho prescrito, planificado e realizado no âmbito da formação continuada em matemática.

4) Releitura do documento da área de Matemática na BNCC e dos textos das oficinas para análise mais detalhada do trabalho com a resolução de problemas, partindo dos procedimentos:

- Observação das condutas dos professores atuantes na formação continuada, antes e depois das tarefas (BRONCKART, 2006).

- Produções dos professores, focando a resolução de problemas no âmbito da formação.

Esses momentos foram possíveis a partir da constituição do grupo participante da formação continuada em Matemática, que contribuiu para a leitura e a análise discursiva dos objetos do conhecimento e das habilidades, propostos na unidade temática Números, por meio da vivência da oficina Brincando, cantando, jogando e problematizando também se aprende a Matemática! e da produção de textos, em que os professores participantes evidenciaram concepções e experiências do trabalho com a resolução de 
problemas em aulas de Matemática nos Anos Iniciais do Ensino Fundamental.

\section{O trabalho do professor que ensina Matemática com a resolução de problemas proposta na BNCC}

A resolução de problemas como recurso metodológico no processo de ensinoaprendizagem da Matemática precisa ser discutida e vivenciada nos encontros de formação com professores que ensinam Matemática. Na organização dos cursos de formação continuada de professores, segundo Oliveira e Passos (2014, p. 70), "é importante permitir-lhes a vivência do conhecimento teórico e do conhecimento prático, levando em consideração as experiências, os saberes e as aprendizagens da sua prática profissional ao longo da formação".

Nos encontros formativos, procuramos promover essas vivências com a resolução de problemas, por meio da análise do texto prescrito na BNCC e da oficina Brincando, cantando, jogando e problematizando também se aprende a Matemática!. Nessa oficina foram discutidos textos, relatadas experiências de sala de aula, realizadas rodas de conversa sobre a resolução de problemas na BNCC, promovidas dinâmicas, elaboradas e resolvidas situações-problema, vivenciados jogos, entre outras atividades.

Nesse trabalho com professores que ensinam Matemática, vivenciamos o que as prescrições da área de Matemática na BNCC deixam de apresentar e de discutir sobre o trabalho com a resolução de problemas na formação e na prática docente, "em um ambiente coletivo e na interação com a atividade discente" (ÉRNICA, 2004, p. 110). Por meio do trabalho individual, em dupla ou grupos, o processo de desenvolvimento da metodologia da resolução de problemas, no contexto das atividades propostas na oficina, buscou mostrar aos professores as possibilidades de aprender Matemática por meio da resolução de problemas.

Na BNCC há uma concepção abrangente de resolução de problemas relacionada ao desenvolvimento e à operacionalização das habilidades matemáticas, conforme Andreatta e Allevato (2018, p. 10), “em que primeiro o aluno aprende matemática para aplicar o conhecimento em resolver problemas, ou seja, o aluno não aprende a resolver problemas e nem aprende matemática resolvendo problemas, como proposto nos PCN". Nesse sentido, corroboramos a resolução de problemas como ponto de partida da 
atividade matemática para a construção de novos conceitos e novos conteúdos no processo de ensino-aprendizagem desse componente curricular por meio da resolução de problemas (BRASIL, 1997; ONUCHIC e ALLEVATO, 2011).

No texto prescrito da BNCC analisado - Área da Matemática, Matemática no Ensino Fundamental - Anos Iniciais: Unidades Temáticas, Objetos de Conhecimento e Habilidades e a Unidade Temática Números — não há considerações sobre as concepções de resolução de problemas e sobre a metodologia da resolução de problemas em aulas de Matemática. Destacam-se, nesse documento, inserções da formulação e da resolução de problemas, utilizando diferentes estratégias, na enunciação das competências gerais, das competências específicas e na unidade temática Números pesquisada neste trabalho.

Compreendemos a resolução de problemas como uma metodologia desafiadora, problematizadora e dinâmica no processo de ensino-aprendizagem da Matemática, que oportuniza aos estudantes, com os novos conhecimentos matemáticos discutidos no trabalho grupal, nos espaços formativos para resolver os problemas propostos pela mediadora da aula ou por eles criados, experimentar e dar sentido aos conhecimentos que já têm.

$\mathrm{Na}$ leitura e na pesquisa dos termos "problemas e resolução de problemas" no texto prescrito da BNCC, marcando a unidade temática Números nos Anos Iniciais do Ensino Fundamental, encontramos as seguintes estruturas frasais, no que se refere ao trabalho com a resolução de problemas: "a formulação e a resolução de problemas"; "os processos matemáticos de resolução de problemas"; "resolver problemas cotidianos, sociais e de outras áreas de conhecimento"; "enfrentar situações-problema em múltiplos contextos"; "busca de soluções para problemas"; "resolvam problemas com números naturais e números racionais cuja representação decimal é finita"; "complexidade das situações-problema propostas, cuja resolução exige a execução de mais etapas ou noções de unidades temáticas distintas"; "resolver e elaborar problemas envolvendo..."; "formulem problemas em outros contextos" (BRASIL, 2017, p. 263-295).

Esses aspectos referentes à resolução de problemas foram apresentados, discutidos e vivenciados no texto prescritivo, no texto planificado e no trabalho realizado na oficina desenvolvida nos encontros formativos dos dias 24 de maio e 28 de junho de 2019, que buscou discutir sobre a unidade temática Números e a resolução de problemas 
e evidenciar as estruturas frasais identificadas e analisadas na BNCC. Para isso, utilizouse da leitura e da discussão de textos; da vivência da metodologia da resolução de problemas no contexto de jogos, histórias, músicas, leitura de imagens, dentre outras atividades apresentadas na formação continuada; e da elaboração de problemas matemáticos com diferentes estratégias de resolução e de dinamização do trabalho com essa metodologia de ensino-aprendizagem da Matemática.

Discutimos, nesses encontros formativos, as concepções de alguns autores sobre a resolução de problemas, considerando os saberes e as experiências do grupo participante da formação continuada em relação a essa metodologia em aulas de Matemática: "um caminho para o ensino de Matemática” (BRASIL, 1997, p. 42); “o problema é ponto de partida e, na sala de aula, através da resolução de problemas, os alunos devem fazer conexões entre diferentes ramos da Matemática, gerando novos conceitos e novos conteúdos" (ONUCHIC e ALLEVATO, 2011, p. 81); "um problema é definido como qualquer tarefa ou atividade na qual os estudantes não tenham nenhum método ou regras prescritas ou memorizadas, nem a percepção de que haja um método específico para chegar à solução correta" (VAN DE WALLE, 2009, p. 57); dentre outras. Esses aspectos conceituais permeiam as ideias compartilhadas sobre a resolução de problemas pelos professores que ensinam matemática.

Para a professora Ana, "a resolução de problemas é de extrema importância para o desenvolvimento do raciocínio lógico dos alunos, deve ser trabalhada em todas as unidades temáticas da Matemática”. A esse respeito, as indicações da resolução de problemas nas unidades temáticas da Matemática, segundo Andreatta e Allevato (2018, p. 9-10), “estão relacionadas à perspectiva de primeiro o aluno aprender determinado conteúdo para depois elaborar e/ou resolver problemas. Nas demais unidades temáticas — Geometria, Probabilidade e Estatística — não identificamos abordagens à RP”.

A professora Ana ressalta a importância do trabalho com a resolução de problemas em todas as unidades temáticas, para propiciar a construção de aprendizagens significativas em Matemática. Assim, devem-se fazer as alterações necessárias nos objetos do conhecimento e nas habilidades apresentados na BNCC, levando em consideração cada unidade temática, ano a ano, e a vivência dessa metodologia de ensinoaprendizagem na formação e na prática docente. 
Para retomada dos conceitos matemáticos e aprofundamento teórico e prático ano a ano, conforme salienta esse documento curricular, é imprescindível o investimento na formação continuada de professores que ensinam Matemática, visto que o encontro com os pares no local de formação contribuirá para discutir e compreender os fundamentos teórico-metodológicos dessa disciplina. A muitos desses professores, segundo Oliveira e Passos (2014, p. 74), "faltam oportunidades de vivenciar projetos de formação matemática que discutam novas abordagens do ensino de matemática, para atender às atuais exigências da sociedade, levando em consideração os saberes e as experiências da própria prática profissional”.

A iniciativa da Secretaria Municipal de Educação de uma rede de ensino, em uma cidade de Minas Gerais, de propiciar aos professores dos Anos Iniciais do Ensino Fundamental o estudo e o aprofundamento teórico e prático da área de Matemática na BNCC possibilitou que construíssem conhecimentos matemáticos e didáticopedagógicos, pela vivência da metodologia da resolução de problemas, ao desenvolver jogos e outras estratégias teórico-metodológicas partilhadas nos encontros formativos.

Nos excertos das professoras, percebem-se as concepções e as contribuições da resolução de problemas como metodologia de ensino-aprendizagem no trabalho prescrito, planificado e realizado no âmbito da formação: "É tudo que Sandra falou como explanar a situação-problema” (Carla); "Acredito que abre um leque para se realizar um trabalho interdisciplinar e contribui para uma aprendizagem efetiva e significativa" (Carolina); "Levar o aluno a pensar, concluir, buscar soluções e chegar a própria conclusão" (Catarina); "Auxilia na interpretação, a pensar, com ações e para o seu desenvolvimento" (Edna); "Lidamos sempre com situações que envolvem discussões, e com a resolução de problemas instigamos os alunos a pensarem de maneira prazerosa" (Gabriela); "O aluno é colocado em uma situação de desafios. Ao ser desafiado, ele precisa solucionar. Então, a resolução de problemas contribui significativamente para o aprendizado da matemática" (Marta); "Estimular o raciocínio do aluno, levando a questionar e criar estratégias na resolução" (Natália); "Ferramenta, estratégia presente para garantir aprendizagem ampla e significativa" (Patrícia).

Essas professoras ressaltam as possibilidades para realizar um trabalho interdisciplinar e uma aprendizagem significativa da Matemática, considerando assim as 
discussões e as diferentes estratégias que podem ser criadas no processo da resolução de problemas. Dessa forma, “ensinar matemática através da resolução de problemas é a abordagem mais consistente com as recomendações do NCTM e dos PCN, pois conceitos e habilidades matemáticas são aprendidos no contexto de resolução de problemas" (ANDRADE e ONUCHIC, 2017, p. 438).

No que se refere às estratégias no processo de resolução de problemas, há algumas inserções na BNCC, com destaque em parte das habilidades da unidade temática Números de $1^{\circ}$ ao $5^{\circ}$ ano, analisada neste artigo. A utilização de estratégias pessoais ou convencionais e formas de registro pessoais, tais como cálculo exato ou aproximado, incluindo cálculo mental, cálculo por estimativa, algoritmos, dentre outras, está apresentada nesse documento, na habilidade de resolver e elaborar problemas de adição, subtração, multiplicação e divisão, considerando os objetos de conhecimento envolvendo problemas (BRASIL, 2017).

O que esse texto prescrito pontua vivenciamos na formação continuada, por meio da resolução de problemas como metodologia de ensino-aprendizagem, a qual oportunizou ao grupo participante experienciar "múltiplos pontos de partida — diferentes lugares por onde começar o problema - diferentes caminhos para se chegar às soluções" (VAN DE WALLE, 2009, p. 70) dos problemas propostos em atividades desenvolvidas na oficina Brincando, cantando, jogando e problematizando também se aprende a Matemática!. A esse respeito, quando a professora Carla salienta a resolução de problemas como "é tudo que Sandra falou como explanar a situação-problema”, enfatiza o contexto do trabalho prescrito, planificado e realizado com a resolução de problemas na formação continuada de professores, visto que, nos encontros formativos, discutimos o que esse documento aponta e as respectivas lacunas e destacamos as pesquisas desenvolvidas na área de Educação e Educação Matemática sobre a resolução de problemas em aulas de Matemática e na formação docente.

Essa concepção da professora se refere também às diferentes estratégias teóricometodológicas vivenciadas nessa oficina que discutiu o trabalho com a resolução de problemas no contexto da unidade temática Números, proposta na BNCC. Foi possível desenvolver essa metodologia em conexão com as vivências de rodas de conversas, jogos, brincadeiras, dinâmicas, músicas e relatos de experiências produzidos e compartilhados 
pelos professores nos encontros formativos.

Quando as professoras Catarina, Edna, Gabriela e Natália salientam que a resolução de problemas envolve os estudantes nas discussões matemáticas para pensar e chegar à própria solução do problema de maneira prazerosa, corroboram a afirmação de Van de Walle (2009, p. 57): "as tarefas ou problemas podem e devem ser propostos de modo a envolver os alunos no pensar e desenvolver a matemática importante que eles precisam aprender".

Esse autor ainda ressalta que, "ao resolver o problema ou fazer a atividade, os alunos devem estar preocupados principalmente em dar significado à Matemática envolvida e, assim, desenvolver sua compreensão sobre essas ideias" (VAN DE WALLE, 2009, p. 58). Também numa formação continuada de Matemática, os problemas devem ser apresentados de forma que os professores participem da dinamização do trabalho com a resolução do problema e atribuam significado à Matemática envolvida no processo de ensino-aprendizagem.

Nos textos sobre a resolução de problemas produzidos pelas professoras participantes da formação continuada estão conectadas as relações entre a prescrição, a planificação e o trabalho efetivamente realizado no contexto das diferentes atividades vivenciadas na oficina, envolvendo, além de outros elementos, histórias infantis, dinâmicas, brincadeiras, jogos, leitura de imagens, músicas, criação de problemas, que propiciaram reflexões sobre as possibilidades do trabalho com os objetos do conhecimento e as habilidades, propostos na unidade temática Números, considerando as experiências da formação e da prática docente.

\section{As relações entre o trabalho prescrito, o planificado e o realizado no agir docente com a resolução de problemas na formação continuada em matemática}

$\mathrm{Na}$ oficina Brincando, cantando, jogando e problematizando também se aprende a Matemática!, o trabalho prescrito, o trabalho planificado e o trabalho realizado apresentaram-se nos textos dessa atividade formativa, produzidos pela professoraformadora e pelos professores participantes da formação, num processo de trabalho colaborativo durante as vivências das ações propostas e criadas no âmbito desse percurso formativo que envolveu as seguintes dimensões do agir docente: pessoal, interacional, 
mediada, interpessoal, impessoal e transpessoal (MACHADO e BRONCKART, 2009), nas vivências de atividades diversificadas que possibilitaram aprender Matemática com prazer e entusiasmo na interação colaborativa e dialógica com os pares. Também refletimos sobre o brincar, o cantar, o jogar e o problematizar nas aulas de matemática na educação básica e superior, "portanto, é essencial que o professor vivencie na sala de aula o lúdico como princípio norteador das atividades didático-pedagógicas" (OLIVEIRA, 2018, p. 85-86).

Ao participarem dessa oficina, os professores mostraram satisfação, alegria, entusiasmo, envolvimento e compartilhamento de saberes-fazeres didático-pedagógicos de suas experiências formativas. Nesse contexto, corroboramos a afirmação de Freire (1996, p. 160-161): “a alegria não chega apenas no encontro do achado mas faz parte do processo da busca. E ensinar e aprender não podem dar-se fora da procura, fora da boniteza e da alegria [...], a alegria necessária ao que-fazer docente”.

A professora-formadora apresentou oralmente o texto prescritivo da oficina que contém, no projeto, os objetivos, o resumo da proposta do trabalho, a introdução com reflexões teóricas, os procedimentos metodológicos de cada atividade apresentada, os recursos necessários para o desenvolvimento das ações pedagógicas, a avaliação dos momentos experienciados na oficina, as referências utilizadas na oficina e as sugestões de leituras complementares sobre os conteúdos matemáticos discutidos na formação.

Discutimos com os professores o plano da formação considerado como texto planificador (MACHADO, 2002), com sugestões de ações a serem desenvolvidas com a participação dos professores que buscam criar estratégias "para a aprendizagem de conteúdos e para o desenvolvimento de capacidades a eles relacionadas" (CORRÊA, 2014, p. 348). Nesse contexto, o agir docente é orientado "na interação com diferentes outros que, de forma direta ou indireta, estão envolvidos na situação" (MACHADO, 2007, p. 93). Nas relações com os outros, as atividades propostas na oficina foram desenvolvidas e criadas. Assim, compartilhamos aqui alguns textos das 15 professoras selecionadas para compor os dados analisados neste artigo.

No encontro formativo realizado no dia 29 de novembro de 2019, os professores tiveram a oportunidade de registrar seu olhar sobre a formação continuada em Matemática, respondendo o questionário sobre a formação continuada em matemática. 
Esse instrumento metodológico foi pensado e elaborado "para servir como uma fonte complementar de informações" (FIORENTINI e LORENZATO, 2006, p. 117) sobre os encontros formativos realizados com a participação de professores que ensinam Matemática. Desse modo, as nove questões apresentadas no questionário apontam reflexões sobre os momentos experienciados na formação e na prática docente.

Assim, a proposta aos professores no questionário: "A unidade temática 'Números' aponta nas habilidades a resolução e elaboração de problemas nas aulas de matemática. Descreva uma atividade com a resolução ou elaboração de problemas desenvolvida na turma em que está atuando este ano de 2019”, a professora Beatriz respondeu: "A atividade mais recente foi os Poemas Problemas que trouxeram novas formas de apresentar problemas vindo de versos". Os resultados dessa atividade vivenciada na formação continuada e na prática pedagógica dessa professora serão compartilhados nesta seção.

Os poemas problemas (BUENO, 2012) apontados por essa professora, no trabalho realizado em aulas de Matemática do $1^{\circ}$ ano do Ensino Fundamental, foram apresentados, discutidos e vivenciados na oficina realizada no dia 24 de maio de 2019, proporcionando o diálogo e as problematizações sobre os significados da adição, subtração, multiplicação e divisão nos Anos Iniciais, a partir do estudo e das reflexões sobre a unidade temática Números nesse nível de ensino. No planejamento dessa estratégia teórico-metodológica vivenciada na oficina, a professora-formadora apresentou no texto prescritivo as seguintes ações compartilhadas no Quadro 1 para dinamização da metodologia da resolução de problemas.

Quadro 1: Poemas Problemas em conexão com a metodologia da resolução de problemas

Apresentação do poema problema: Meu aquário, pela professora mediadora do encontro formativo.

Leitura compartilhada do poema problema.

NO AQUÁRIO QUE COMPREI

HÁ 2 PEIXES VERMELHINHOS,

UM LARANJA, QUE É O REI,

E MAIS 9 AMARELINHOS.

AO TODO, NADANDO JUNTOS,

QUANTOS SÃO OS PEIXINHOS?

Questões referentes ao poema problema: 
" Todos compreenderam o poema problema?

- Vocês querem esclarecimento acerca do poema problema?

Distribuição do poema problema: Meu aquário, para os professores participantes da formação. Resolução do problema.

Registro por escrito do processo de resolução do poema problema proposto.

Compartilhando as ideias - cada professor(a) apresenta os resultados obtidos, explicando as estratégias utilizadas na resolução do problema.

Síntese das ideias apresentadas pelos professores.

Exposição dialogada sobre os significados, as ideias, os conceitos e os cálculos da adição e da subtração.

Resolução de problemas do campo aditivo por meio do desenvolvimento de diferentes caminhos para a resolução de problemas.

Fonte: Acervo da Oficina

Por meio dessa proposta, os professores experienciaram a metodologia da resolução de problemas na formação e, posteriormente, nas turmas em que atuam como professores de Matemática. Assim, foi possível ao grupo a dinamização dessa atividade por meio dos momentos propostos por Van de Walle (2009, p. 61): "antes, durante e depois" e do roteiro de atividades que permite vivenciar essa metodologia com mais entusiasmo em suas salas de aula e proporciona aos estudantes um olhar mais confiante (ONUCHIC e ALLEVATO, 2011) no processo de ensino-aprendizagem da Matemática.

Para resolução do poema problema Meu aquário, a professora-formadora utilizou o roteiro de atividades - formação de grupos, preparação do problema, leitura individual, leitura em conjunto, resolução do problema, observação e incentivo, registro das resoluções na lousa, plenária, busca do consenso, formalização do conteúdo (ANDRADE e ONUCHIC, 2017; ONUCHIC e ALLEVATO, 2011) em conexão com a proposta dos momentos "antes, durante e depois".

No primeiro momento, o "antes", com a familiarização com o poema problema, os professores comunicaram oralmente terem compreendido a tarefa proposta no contexto da dinamização da metodologia da resolução de problemas. Nessa ação do trabalho docente, a dimensão pessoal envolveu expectativas, compreensão e conhecimentos prévios dos resolvedores do problema. E a dimensão mediada por instrumentos contemplou a utilização do poema problema Meu aquário (BUENO, 2012, p. 4-5) compartilhado no livro, na coletânea de textos da oficina e exibido em slide no datashow. 
Ao apresentar esse problema, a professora-formadora solicitou a leitura individual e a leitura nos grupos formados para discussão e resolução do problema. Nessa etapa, "se houver dificuldade na leitura do texto, o próprio professor pode auxiliar os alunos, lendo e levando-os a interpretar o problema” (ANDRADE e ONUCHIC, 2017, p. 439). Ao ler o poema problema, os professores, na maioria, ficaram encantados, pois não conheciam o tipo de problema apresentado. Também expressaram oralmente as possibilidades do trabalho interdisciplinar entre a Matemática e a Língua Portuguesa e outras áreas do conhecimento.

No segundo momento, o "durante", os professores resolveram o poema problema individualmente, assumindo uma postura ativa e de engajamento no desenvolvimento da ação (BRONCKART, 2008), criando diferentes estratégias, conforme a Figura 1.

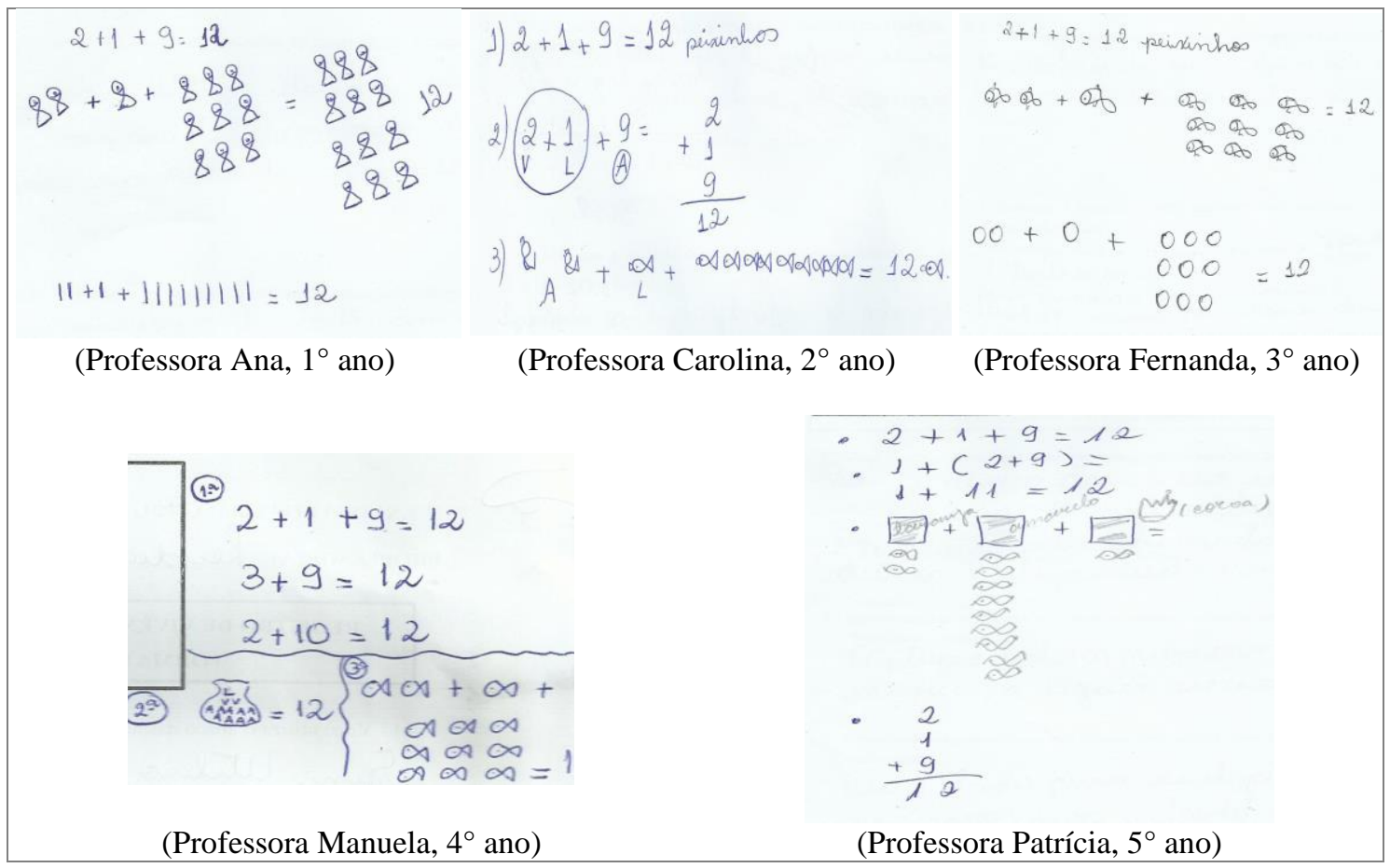

Figura 1: Resolução do poema problema "Meu aquário" (Dados da Pesquisa)

No processo da resolução do poema problema, essas professoras utilizaram diferentes registros de representação — desenho, algoritmo, cálculo mental e esquema. Mesmo o poema problema tendo sido resolvido individualmente, as dimensões interacional e interpessoal entrelaçaram esse momento, visto que as professoras comunicavam as estratégias na interação com os outros que estavam no ambiente da formação, participando dessa atividade. Nesse percurso, a professora-formadora atuou como orientadora, observou o envolvimento do grupo na resolução do problema e 
forneceu "sugestões adequadas baseadas nas ideias" dos professores "e nos seus modos de pensamento" (VAN DE WALLE, 2009, p. 64), apontando a importância de utilizar diferentes estratégias na resolução do poema problema.

A partir do entendimento do poema problema, os professores participantes da formação buscaram resolvê-lo, registrando diferentes estratégias em um trabalho cooperativo e colaborativo. Ao vivenciar essa etapa, "considerando os alunos como coconstrutores da matemática nova que se quer abordar, o problema gerador é aquele que, ao longo de sua resolução, conduzirá os alunos para a construção do conteúdo planejado pelo professor para aquela aula" (ONUCHIC e ALLEVATO, 2011, p. 83-84).

Nessa etapa, no processo da resolução do poema problema e outros, a professoraformadora buscou observar e estimular o trabalho colaborativo e incentivar o compartilhamento de ideias (ANDRADE e ONUCHIC, 2017) entre os pares, no desenvolvimento de estratégias para resolver os problemas propostos na formação continuada em Matemática. Foram perceptíveis a interação e o envolvimento entre os professores para registrar diferentes métodos de resolução do problema Meu aquário.

No terceiro momento, o "depois", os professores compartilharam as suas ideias na resolução do poema problema, e a professora-formadora mediou a discussão, enquanto os professores apresentavam as diferentes estratégias utilizadas. No final das discussões, ela sintetizou as ideias principais compartilhadas e formalizou "os novos conceitos e novos conteúdos construídos" (ONUCHIC e ALLEVATO, 2005, p. 221).

As diferentes resoluções do poema problema foram discutidas e registradas na lousa por representantes de professores dos grupos do $1^{\circ}$ ao $5^{\circ}$ ano. Posteriormente, na formalização do conteúdo, a professora-mediadora refletiu sobre "os conceitos, os princípios e os procedimentos construídos através da resolução do problema, destacando as diferentes técnicas operatórias e as demonstrações das propriedades qualificadas sobre o assunto" (ONUCHIC e ALLEVATO, 2011, p. 85).

Na Figura 1, há algumas estratégias que foram compartilhadas pelas professoras no encontro formativo do dia 24 de maio de 2019. Nas discussões do resultado do poema problema, a professora-formadora refletiu sobre a importância da resolução de problemas no processo de ensino-aprendizagem da Matemática. Dialogou e problematizou com os professores participantes da formação os significados, os conceitos e os cálculos da 
adição, a partir do poema problema $\mathrm{Meu}$ aquário. Também promoveu a construção de novos conceitos e novos conteúdos no contexto do enunciado e do resultado dessa atividade, por meio dos questionamentos: “O que o 12 significa na Matemática?”, "Nos versos do poema problema há números pares e ímpares?", “Qual a diferença entre o número de peixes amarelinhos e os vermelhinhos?", "Se no aquário tivesse quatro peixes vermelhinhos, qual seria a quantidade de peixinhos?" "Quero dividir a quantidade de peixinhos entre minha amiga. Com quanto cada uma ficaria?’.

A utilização da resolução desse poema problema e de outros, sugeridos por Bueno (2012), no âmbito da formação continuada, propiciou aos professores a compreensão da importância dessa metodologia nas aulas de Matemática. Foi possível discutir nesse problema os conceitos matemáticos: Sistema de Numeração Decimal, números pares e ímpares, adição, subtração, multiplicação e divisão, campo aditivo, campo multiplicativo, dentre outros, a partir da construção de problematizações e de poema problema.

Essas tarefas foram guiadas pelo agir individual e coletivo, considerando as dimensões pessoal, interacional, mediada, interpessoal, impessoal e transpessoal (MACHADO e BRONCKART, 2009) no trabalho prescrito, planificado e realizado (MACHADO, 2002) no contexto da oficina e das atividades propostas para discutir a resolução de problemas no âmbito da unidade temática Números, compartilhada neste artigo.

Em relação a essa unidade temática, a BNCC destaca: "tem como finalidade desenvolver o pensamento numérico, que implica o conhecimento de maneiras de quantificar atributos de objetos e de julgar e interpretar argumentos baseados em quantidades" (BRASIL, 2017, p. 266). Para essa construção, conforme o documento, é necessário propor para a formação de professores o estudo dos fundamentos teóricopráticos dos números e das operações, para vivenciar com os estudantes dos anos iniciais os significados da adição, da subtração, da multiplicação e da divisão, dentre outros conteúdos de matemática, através da resolução de problemas.

\section{Considerações finais}

A oficina Brincando, cantando, jogando e problematizando também se aprende a Matemática! proporcionou a exposição dialogada dos conteúdos matemáticos dos Anos 
Iniciais do Ensino Fundamental contemplados na unidade temática Números. Desse modo, vivenciamos na formação a metodologia da resolução de problemas em conexão com os jogos e com outras perspectivas de ensino-aprendizagem da Matemática.

Esse trabalho com a resolução de problemas no contexto da unidade temática Números, proposta na BNCC, não foi discutido de forma isolada, mas sim interligada no trabalho prescrito, planificado e realizado com a Álgebra, Geometria, Grandezas e Medidas, Probabilidade e Estatística.

As bases do Interacionismo Sociodiscursivo (ISD) propiciaram o entendimento das representações textualizadas construídas pelo grupo de professoras participantes deste estudo, na dinamização da metodologia da resolução de problemas, a partir do trabalho prescrito, planificado e realizado (MACHADO, 2002) no âmbito da formação continuada, que apresentou, discutiu e vivenciou os objetos do conhecimento e as habilidades propostos, principalmente, sobre Números.

Neste estudo, compartilhamos resultados e reflexões sobre a resolução de problemas na BNCC e na proposta apresentada na oficina, por meio da análise das atividades teóricas e práticas vivenciadas que oportunizaram aos professores compreenderem a importância, para o estudo e a elaboração de propostas pedagógicas que contribuam para a melhoria do processo de ensino-aprendizagem da Matemática, do trabalho colaborativo entre os pares.

Os princípios do ISD também revelaram a relevância de conhecer não somente os conteúdos da matriz curricular de Matemática da turma que atua como professor. Nesse sentido, destacaram que a formação continuada propiciou conhecer teoricamente e na prática e analisar criticamente o que cada unidade temática apresenta em Matemática nos Anos Iniciais do Ensino Fundamental. As rodas de conversas proporcionaram o diálogo sobre a área de Matemática na BNCC.

Os textos produzidos pelas professoras, no contexto dos conteúdos matemáticos tematizados na formação continuada, possibilitam inferir que as partícipes (re)configuram os sentidos da resolução de problemas durante as interações dialógicas e problematizadoras entre os pares, nos momentos vivenciados na oficina, que proporcionaram às professoras conhecer e participar da dinamização da metodologia da resolução de problemas, por meio dos momentos propostos por Van de Walle (2009) - 
antes, durante e depois -, e por intermédio de outros pesquisadores, os quais potencializaram reflexões sobre os elementos constitutivos do agir docente (MACHADO e BRONCKART, 2009) e novas possibilidades de (re)organizar o seu trabalho com a resolução de problemas como metodologia de ensino-aprendizagem nas aulas de Matemática.

No processo da resolução do poema problema Meu aquário (BUENO, 2012), dentre outras atividades partilhadas na formação, tais como: dinâmicas, jogos, brincadeiras, histórias infantis, dinamização de músicas, leitura de imagem, criação de situações-problemas, as dimensões pessoal, interacional, mediada, interpessoal, impessoal e transpessoal (MACHADO e BRONCKART, 2009) estão conectadas pelo agir individual e coletivo do grupo que se encontrou no espaço da formação continuada para estudar, vivenciar e analisar criticamente o texto prescritivo da área de Matemática dos Anos Iniciais do Ensino Fundamental proposto na BNCC, fazendo as alterações necessárias nos textos do trabalho planificado e do trabalho realizado.

Nesse contexto, conforme relatos de experiências das professoras participantes da formação, a oficina realizada nos encontros formativos compartilhados neste artigo propiciou a construção de outras concepções em relação à resolução de problemas nas aulas de Matemática. Esses encontros também evidenciaram que essa metodologia é essencial na prática pedagógica, visto que possibilita pensar matematicamente, refletir sobre situações cotidianas, realizar um trabalho interdisciplinar, vivenciar a leitura, a escrita e a produção de textos, inserir a resolução de problemas em conexão com os jogos, a literatura infantil, a leitura de imagem, a música, dentre outras possibilidades.

A formação continuada provocou mudanças nas relações das participantes em relação aos aspectos conceituais e metodológicas sobre o trabalho com a resolução de problemas e com os números nas aulas de Matemática, levando em consideração o estudo e a análise crítica dos objetos do conhecimento e das habilidades propostos na unidade temática Números e a importância de oportunizar aos professores que ensinam Matemática a vivência do conhecimento teórico e prático na formação continuada.

Esses percursos formativos e o compartilhamento de resultados de pesquisas acadêmicas foram experienciados na formação continuada com a participação de professores que ensinaram-aprenderam os conteúdos de Matemática numa perspectiva 
colaborativa com a professora-formadora, que buscou valorizar os saberes, as experiências e as aprendizagens do grupo.

\section{Referências}

AMIGUES, René. Trabalho do professor e trabalho de ensino. In: MACHADO, Anna Rachel. (Org.). O ensino como trabalho: uma abordagem discursiva. Londrina: EdUEL, 2004, p. 35-53.

ANDRADE, Cecília Pereira de; ONUCHIC, Lourdes de la Rosa. Perspectivas para a resolução de problemas no GTERP. In: ONUCHIC, Lourdes de la Rosa; LEAL JUNIOR, Luiz Carlos; PIRONEL, Márcio. (Org.). Perspectivas para resolução de problemas. São Paulo: Livraria da Física, 2017, p. 433-464.

ANDREATTA, Cidimar; ALLEVATO, Norma Suely Gomes. A resolução de problemas nos documentos de orientação curricular oficiais da educação básica brasileira. In: SEMINÁRIO INTERNACIONAL DE PESQUISA EM EDUCAÇÃO MATEMÁTICA, 7, 2018, Foz do Iguaçu. Anais do VII SIPEM. Foz do Iguaçu: SBEM, 2018, p. 1-12.

BAKHTIN, Mikhail. Estética da criação verbal. Tradução de Paulo Bezerra. São Paulo: Martins Fontes, 2011.

BONOTTO, Danusa de Lara. (Re)configurações do agir modelagem na formação continuada de professores de Matemática da Educação Básica. 2017. 310f. Tese (Doutorado em Educação em Ciências e Matemática) - Escola Politécnica. Pontifícia Universidade Católica do Rio Grande do Sul. Porto Alegre.

BRASIL. Ministério da Educação. Secretaria de Educação Básica. Base Nacional Comum Curricular: Educação Infantil e Ensino Fundamental. Brasília: MEC/SEB, 2017.

BRASIL. Ministério da Educação. Secretaria de Educação Fundamental. Parâmetros Curriculares Nacionais: Matemática. Brasília: MEC/SEF, 1997.

BRONCKART, Jean Paul. Atividade de linguagem, textos e discursos: por um interacionismo sócio-discursivo. Tradução de Anna Rachel Machado e Péricles Cunha. São Paulo: Educ, 1999.

BRONCKART, Jean Paul. Por que e como analisar o trabalho do professor. In: MACHADO, Anna Rachel; MATENCIO, Maria de Lourdes Meirelles. (Org.). Atividades de linguagem, discurso e desenvolvimento humano. Campinas: Mercado de Letras, 2006. p. 203-229.

BRONCKART, Jean-Paul. O agir nos discursos: das concepções teóricas às concepções dos trabalhadores. Tradução de Anna Rachel Machado e Maria de Lourdes Meirelles Matencio. Campinas: Mercado de Letras, 2008.

BUENO, Renata. Poemas problemas. São Paulo: Editora do Brasil, 2012. 
BUENO, Simone; ALENCAR, Edvonete Souza de; MILLONES, Teresa Sofia Oviedo. Reflexões e desafios da resolução de problemas nas aulas de Matemática: um ensaio teórico. Educação Matemática Debate, Montes Claros, v. 1, n. 1, p. 9-27, jan./abr. 2017

CORRÊA, Marcia Cristina. Reflexões sobre o trabalho docente. Desenredo, Passo Fundo, v. 10, n. 2, p. 370-390, jul./dez. 2014.

ÉRNICA, Maurício. O trabalho desterrado. In: MACHADO, Anna Rachel. (Org.). $O$ ensino como trabalho: uma abordagem discursiva. Londrina: EdUEL, 2004, p. 106-130.

FIORENTINI, Dario; LORENZATO, Sergio. Investigação em Educação Matemática: percursos teóricos e metodológicos. Campinas: Autores Associados, 2006.

FREIRE, Paulo. Pedagogia da autonomia: saberes necessários à prática educativa. 18. ed. São Paulo: Paz e Terra, 1996.

GARCÍA, Carlos Marcelo. La evaluación del desarrollo profesional docente. In: GARCÍA, Carlos Marcelo. (Coord.). La evaluación del desarrollo profesional docente. Barcelona: Da Vinci, 2011, p. 11-21.

GARCIA-REIS, Andreia Rezende; SILVA, Andressa Barcellos Correia da. O trabalho docente na versão preliminar do Projeto Pedagógico Institucional para os cursos de licenciaturas. Instrumento, Juiz de Fora, v. 21, n. 1, p. 87-101, jan./jun. 2019.

HABERMAS, Jürgen. Consciência moral e agir comunicativo. Tradução de Guido Antônio de Almeida. Rio de Janeiro: Tempo Brasileiro, 1989.

MACHADO, Ana Raquel; BRONCKART, Jean-Paul. (Re-)configurações do trabalho do professor construídas nos e pelos textos: a perspectiva metodológica do Grupo ALTERLAEL. In: MACHADO, Ana Raquel; ABREU-TARDELLI, Lília Santos; CRISTOVÃO, Vera Lúcia Lopes. (Org.). Linguagem e Educação: o trabalho do professor em uma nova perspectiva. Campinas: Mercado de Letras, 2009. p. 31-77.

MACHADO, Anna Rachel. Por uma concepção ampliada do trabalho do professor. In: GUIMARÃES, Ana Maria de Matos; MACHADO, Anna Rachel; COUTINHO, Antónia (Org.). O Interacionismo Sociodiscursivo: questões epistemológicas e metodológicas. Campinas: Mercado de Letras, 2007.

MACHADO, Anna Rachel. Trabalho prescrito, planificado e realizado na formação de professores: primeiro olhar. Scripta, Belo Horizonte, v. 6, n. 11, p. 39-53, jul./dez. 2002.

MAGALHÃES, Tânia Guedes. Gêneros textuais em pesquisa com professores de Língua Portuguesa: contribuições e desafios da parceria entre universidade e escola. Letras \& Letras, Uberlândia, v. 31, n. 3, p. 100-119, jul./dez. 2015.

MIZUKAMI, Maria da Graça Nicoletti; REALI, Aline Maria de Medeiros Rodrigues; REYS, Cláudia Raimundo; MARTUCCI, Elisabeth Márcia; LIMA, Emilia Freitas de; TANCREDI, Regina Maria Simões Puccinelli; MELLO, Roseli Rodrigues de. Escola e aprendizagem da docência: processos de investigação e formação. 2. reimpr. São Carlos: EdUFSCar, 2006. 
OLIVEIRA, Sandra Alves de. Vamos brincar, jogar e criar com prazer nas aulas de Matemática no curso de Pedagogia! Revista de Investigação e Divulgação em Educação Matemática, Juiz de Fora, v. 2, n. 2, p. 82-96, jul./dez. 2018.

OLIVEIRA, Sandra Alves de; PASSOS, Cármen Lúcia Brancaglion. Resolução de problemas e formação continuada de professores que ensinam Matemática nos Anos Iniciais. In: NUNES, Cláudio Pinto; FAGUNDES, Heldina Pereira Pinto. (Org.). Formação de professores: questões contemporâneas. Curitiba: CRV, 2014, p. 69-89.

ONUCHIC, Lourdes de la Rosa. Ensino-aprendizagem de Matemática através da resolução de problemas. In: BICUDO, Maria Aparecida Viggiani. (Org.). Pesquisa em Educação Matemática. São Paulo: EdUNESP, 1999, p.199-220.

ONUCHIC, Lourdes de la Rosa; ALLEVATO, Norma Suely Gomes. Novas reflexões sobre o ensino-aprendizagem de Matemática através da resolução de problemas. In: BICUDO, Maria Aparecida Viggiani; BORBA, Marcelo de Carvalho. (Org.). Educação Matemática: pesquisa em movimento. 2. ed. rev. São Paulo: Cortez, 2005, p. 213-231.

ONUCHIC, Lourdes de la Rosa; ALlEVATO, Norma Suely Gomes. Pesquisa em resolução de problemas: caminhos, avanços e novas perspectivas. Bolema, Rio Claro, v. 25, n. 41, p. 73-98, dez. 2011.

SAUJAT, Fredéric. O trabalho do professor nas pesquisas em Educação: um panorama. In: MACHADO, Anna Rachel. (Org.) $O$ ensino como trabalho: uma abordagem discursiva. Londrina: EdUEL, 2004, p. 4-34.

SOUZA-E-SILVA, Maria Cecília Perez de. O ensino como trabalho. In: MACHADO, Anna Rachel. (Org.) $O$ ensino como trabalho: uma abordagem discursiva. Londrina: EdUEL, 2004, p. 81-104.

TARDIF, Maurice; LESSARD, Claude. O trabalho docente: elementos para uma teoria da docência como profissão de interações humanas. Tradução de João Batista Kreuch. 5. ed. Petrópolis: Vozes, 2009.

VAN DE WALLE, John Arthur. Matemática no Ensino Fundamental: formação de professores e aplicação em sala de aula. Tradução de Paulo Henrique Colonese. 6. ed. Porto Alegre: Artmed, 2009. 